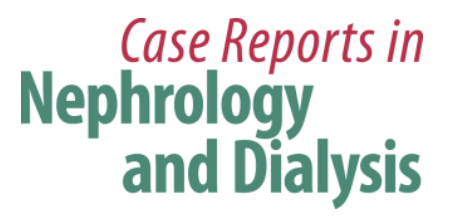

\title{
Giant Brachial Aneurysm after Arteriovenous Fistula Ligation: A Review of the Different Surgical Approaches
}

\author{
Alessia Salerno Marco Leopardi Annamaria Maggipinto \\ Marco Ventura \\ Department of Vascular Surgery, San Salvatore Hospital, University of L'Aquila, \\ L'Aquila, Italy
}

\section{Keywords}

Brachial artery aneurysm · Arteriovenous fistula ligation · Graft

\begin{abstract}
The aim of this paper is to describe the case of a patient successfully treated for left brachial arterial aneurysm occurring 15 years after renal transplantation and consequent 8 years after arteriovenous fistula (AVF) ligation. We describe our experience and our surgical approach. A 45-year-old man presented to our attention for a large pulsatile formation on the volatile face of the left forearm, which he reported to have enlarged in the last year. He had a history of chronic renal impairment in 2000, then AVF for dialysis was realized, and he was finally addressed to kidney transplantation in 2004. In 2011 the AVF was ligated. We observed absence of radial pulse and direct flow on the ulnar artery; a large pulsatile formation was evident along the course of the left brachial artery, associated with forearm venous dilatation. Doppler ultrasound showed fusiform aneurysm of the brachial artery with $3.5 \mathrm{~cm}$ diameter and longitudinal extension of $5 \mathrm{~cm}$ up to the brachial bifurcation. We removed the brachial aneurysm, with a venous bypass on the ulnar artery. The patient was discharged in good general condition on the second postoperative day. At 1 - and 6-month follow-up he had complete recovery with
\end{abstract}




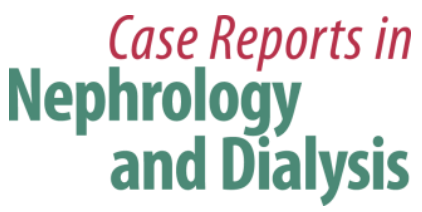

\begin{tabular}{l|l} 
Case Rep Nephrol Dial 2020;10:57-64 \\
\hline DOI: 10.1159/000507427 & $\begin{array}{l}\text { (c) 2020 The Author(s). Published by S. Karger AG, Basel } \\
\text { www.karger.com/cnd }\end{array}$ \\
\hline
\end{tabular}

Salerno et al.: Giant Brachial Aneurysm after Arteriovenous Fistula Ligation

graft patency, without any neurological impairment and with a good esthetic result. An open surgical repair with great saphenous vein interposition seems to be the best choice in terms of patency and perioperative morbidity.

(C) 2020 The Author(s)

Published by S. Karger AG, Basel

\section{Introduction}

Brachial aneurysms after arteriovenous fistula (AVF) ligation are quite rare, their incidence is reported around 5-8\% in operational fistula [1], and if left untreated they can lead to thrombosis and upper limb ischemia [2-4]. Several hypotheses are described, but etiology remains unknown.

The aim of this paper is to describe the case of a patient successfully treated for left brachial arterial aneurysm occurring 15 years after renal transplantation and 8 years after AVF ligation. We describe our experience and our surgical approach.

\section{Case Report}

A 45-year-old man presented to our attention for a large pulsatile formation on the volatile face of left forearm, which he reported to have enlarged in the last year (Fig. 1). At examination, we observed absence of radial pulse and direct flow on the ulnar artery at continuouswave Doppler, and a large pulsatile formation was evident along the course of the left brachial artery, associated with forearm venous dilatation. Further Doppler ultrasound (DUS) examination showed a fusiform aneurysm of the brachial artery with a maximum diameter of $3.5 \mathrm{~cm}$ and longitudinal extension of $5 \mathrm{~cm}$ up to the brachial bifurcation, with thrombus formation, which partially occluded the brachial artery lumen and the origin of the radial artery, which was completely occluded. The cephalic vein after AVF was patent and dilated. The patient had a history of chronic renal impairment "failure" caused by glomerulonephritis in 2000 , then AVF for dialysis was realized in other institution, and finally he was addressed to kidney transplantation in left iliac fossa in 2004. In 2011 the AVF was ligated with suture on the radial artery and the dilated cephalic vein was left in place. A DUS examination performed in 2018 showed patency of the brachial artery with a diameter of $3.5 \mathrm{~cm}$ and patency of the ulnar and radial artery up to the wrist. He also had a computed tomography scan without media contrast, which confirmed the DUS report.

Considering the presence of the diffuse thrombus in the brachial artery and the occlusion of the radial artery occurring in the last year, we decided to remove the brachial aneurysm with a venous bypass on the ulnar artery. The left great saphenous vein (GSV) was studied at DUS and resulted suitable as a graft. The patient was treated under general anesthesia. We first exposed the brachial artery that appeared tenaciously adherent to the surrounding tissues from the midarm to its bifurcation with a bilobed appearance, and satellite brachial veins were collapsed and flattened by the aneurysm. The radial artery was occluded at its origin, and the ulnar artery was soft and pulsating, suitable for bypass anastomoses. Then a proximal portion of about $20 \mathrm{~cm}$ of GSV was removed in the left groin. The radial artery was ligated at the origin. An aneurysmal section of the brachial artery of about $15 \mathrm{~cm}$ was removed. End-to- 


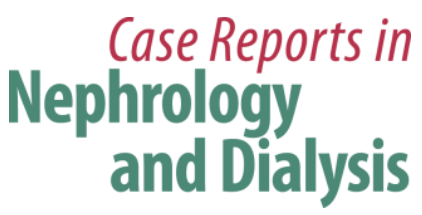

\begin{tabular}{l|l} 
Case Rep Nephrol Dial 2020;10:57-64 \\
\hline DOI: 10.1159/000507427 & $\begin{array}{l}\text { (c) 2020 The Author(s). Published by S. Karger AG, Basel } \\
\text { www.karger.com/cnd }\end{array}$ \\
\hline
\end{tabular}

Salerno et al.: Giant Brachial Aneurysm after Arteriovenous Fistula Ligation

end anastomosis between the venous graft and the brachial artery and the ulnar artery was realized with running polypropylene 6/0 sutures (Fig. 2). The entire aneurysmal cephalic vein was then removed. The patient was discharged in good general condition on the second postoperative day.

One-month control ultrasound showed complete resolution of the aneurysm and graft patency. Clinical examination showed normal upper limb motility, direct flow on the distal ulnar artery, without any neurological impairment, with a good esthetic result. At 6-month follow-up the patient had complete recovery, without any further complications (Fig. 3).

\section{Discussion}

The history of aneurysmal brachial formation after AVF ligation is still unclear. Teixeira et al. [5] hypothesize an upregulation of vasodilator agents, degradation of elastic fibers and amounts of calcium and phosphate deposition due to dialysis, activation of a proinflammatory process in immunosuppression and corticosteroid long-term therapy, and increased resistance of the vessel wall after ligation of the AVF. Others hypothesize that arterial flow in AVF produces an increase in wall stress and a decrease in wall thickness [6]. The alteration of the vascular wall in our patient may have been caused by the long period of dialysis and AVF ligation around 8 years before. The patient presented to our attention without any complications or neurological or vascular impairments, except for asymptomatic radial artery occlusion and presence of the pulsating mass and venous dilatations on the right forearm. Accurate examination of the arm with DUS gave us relevant information, such as the size and the presence of thromboembolic material in the aneurysm and in the distal radial artery, with high risk of thromboembolic and ischemic complications. The patient needed surgical treatment to avoid any possible severe complication, mainly represented by arterial thrombosis, as suggested also by other reports [7, 8]. We preferred an open surgical repair approach with aneurysmectomy and interposition of the GSV, which has been demonstrated to be the treatment of choice in terms of good patency and perioperative morbidity [2, 5, 6, 9-15] as well as reduction of infection in patients treated with immunosuppressive therapy [16]. Several groups have described the validity of the GSV as a graft, with excellent results in terms of patency and absence of complications after intervention [2, 5, 6, 9-15]. One case of arteriomegaly proximal to the GSV has been described and was managed with DUS surveillance [17]. Surgeons generally used the GSV when the aneurysm was very long or when the upper limb vein was not suitable for use [11].

Other authors used the cephalic or basilic ipsilateral vein, with the aim to reduce incisions and, therefore, the duration of the procedure with consequent lower morbidity [18], and to preserve leg veins for future procedures in the arms or other vascular reconstructions $[5,19$ 21]. One aneurysmal degeneration was described after aneurysmectomy and interposition of basilic vein, which was treated with interposition of another ipsilateral arm basilic vein, and one posttraumatic thrombosis that remained untreated due to absence of symptoms [22]. Marzelle et al. [2] described two progressions of pathology after basilic vein interposition bypass that needed secondary polytetrafluoroethylene (PTFE) bypass and one patient treated with allograft which occluded at 12 months. 


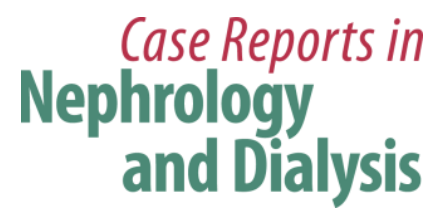

\begin{tabular}{l|l} 
Case Rep Nephrol Dial 2020;10:57-64 \\
\hline DOI: 10.1159/000507427 & $\begin{array}{l}\text { @ } 2020 \text { The Author(s). Published by S. Karger AG, Basel } \\
\text { www.karger.com/cnd }\end{array}$
\end{tabular}

Salerno et al.: Giant Brachial Aneurysm after Arteriovenous Fistula Ligation

When the GSV has to be preserved in patients with cardiovascular risk factors or when it is not suitable as a conduit in chronic venous insufficiency or when other veins are unavailable, a PTFE graft can be used. Several authors used PTFE grafts and showed that a prosthetic graft was a valid alternative; in their individual cases the autologous veins were unavailable $[2,5,12,22-25]$. No complication were described after PTFE grafts.

Resection of an aneurysmal artery with end-to-end anastomosis is described in two reports $[3,22]$. It is reserved for cases of short aneurysm extension, as otherwise there can be wall tension, and in cases where the diameter of the artery remains similar. Table 1 summarizes case reports and series describing treatment for aneurysms after AVF ligation. To the best of our knowledge there are no cases of endovascular therapy for this group of patients.

\section{Conclusions}

According to this review of the therapy of aneurysmal artery after AVF ligation, open surgical repair with GSV interposition seems to be the best choice in terms of patency and perioperative morbidity. In our case the patient presented with radial artery occlusion, so prompt treatment was necessary to avoid further occlusions. Aneurysmectomy and GSV graft bypass proved to be a good option, with no complications observed during surgery or at 6-month follow-up.

\section{Statement of Ethics}

Informed consent for publication was obtained from the patient. The research was conducted ethically in accordance with the World Medical Association Declaration of Helsinki.

\section{Disclosure Statement}

The authors have no conflicts of interest to declare.

\section{Funding Sources}

This work was not supported by any funding sources.

\section{Author Contributions}

All authors participated in the clinical care and assembling of data and contributed to the intellectual content and the writing of the case report. They all actively reviewed and edited the content. 


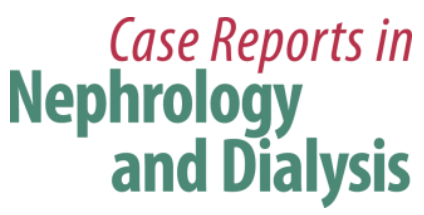

Case Rep Nephrol Dial 2020:10:57-64

(C) 2020 The Author(s). Published by S. Karger AG, Basel www.karger.com/cnd

Salerno et al.: Giant Brachial Aneurysm after Arteriovenous Fistula Ligation

\section{References}

1 Karatepe C, Yetim TG. Treatment of aneurysms of hemodialysis access arteriovenous fistulas. Turk J Thorac Cardiovasc Surg. 2011;19(4):566-9.

2 Marzelle J, Gashi V, Nguyen HD, Mouton A, Becquemin JP, Bourquelot P. Aneurysmal degeneration of the donor artery after vascular access. J Vasc Surg. 2012 Apr;55(4):1052-7.

3 Chemla E, Nortley M, Morsy M. Brachial artery aneurysms associated with arteriovenous access for hemodialysis. Semin Dial. 2010 Jul-Aug;23(4):440-4.

4 Cleveland EC, Sinno S, Sheth S, Sharma S, Mussa FF. Neurovascular compromise due to true brachial artery aneurysm at the site of a previously ligated arteriovenous fistula: case report and review of literature. Vascular. 2015 Dec;23(6):668-72.

5 Teixeira S, Pinto PS, Veiga C, Silva I, Almeida R. Aneurysmal Degeneration of the Bra chial Artery after Vascular Access Creation: Surgical Treatment Results. Int J Angiol. 2017 Sep;26(3):186-90.

6 Dammers R, Tordoir JH, Kooman JP, Welten RJ, Hameleers JM, Kitslaar PJ, et al. The effect of flow changes on the arterial system proximal to an arteriovenous fistula for hemodialysis. Ultrasound Med Biol. 2005 Oct; 31(10):1327-33.

7 Gray RJ, Stone WM, Fowl RJ, Cherry KJ, Bower TC. Management of true aneurysms distal to the axillary artery. J Vasc Surg. 1998 Oct;28(4):606-10.

8 Tetik O, Ozcem B, Calli AO, Gurbuz A. True brachial artery aneurysm. Tex Heart Inst J. 2010;37(5):618-9.

9 Keuter XH, Planken RN, van der Sande FM, Tordoir JH. Brachial artery thrombosis due to haemodialysis arteriovenous fistula. Nephrol Dial Transplant. 2006 Mar;21(3):829-30.

10 Nguyen DQ, Ruddle AC, Thompson JF. Late axillo-brachial arterial aneurysm following ligated BresciaCimino haemodialysis fistula. Eur J Vasc Endovasc Surg. 2001 Oct;22(4):381-2.

11 Orhan A, Özergin U. A huge true axillobrachial aneurysm following arteriovenous fistula ligation. EJCM. 2019;7(2):94-7.

12 Kordzadeh A, Raquel M, D’Espiney B, Ahmad AS, Hanif MA, Panayiotopoulos YP. Donor artery aneurysm formation following the ligation of haemodialysis arteriovenous fistula: a systematic review and case reports. J Vasc Access. 2015 Jan-Feb;16(1):5-12.

13 Garza R 3rd, Dangleben DA, Welkie JF. Brachial artery aneurysm with "blue finger syndrome" after ligation of a remote brachial artery-cephalic vein fistula. Vasc Endovascular Surg. 2013 Aug;47(6):479-81.

14 Hale PC, Linsell J, Taylor PR. Axillary aneurysm: an unusual complication of haemodialysis. Eur J Vasc Surg. 1994 Jan;8(1):101-3.

15 Eugster T, Wigger P, Bölter S, Bock A, Hodel K, Stierli P. Brachial artery dilatation after arteriovenous fistulae in patients after renal transplantation: a 10-year follow-up with ultrasound scan. J Vasc Surg. 2003 Mar; 37(3):564-7.

16 Fendri J, Palcau L, Cameliere L, Coffin O, Felisaz A, Gouicem D, et al. True brachial artery aneurysm after arteriovenous fistula for hemodialysis: five cases and literature review. Ann Vasc Surg. 2017 Feb;39:228-35.

17 Khalid U, Parkinson F, Mohiuddin K, Davies P, Woolgar J. Brachial artery aneurysms following brachiocephalic AV fistula ligation. J Vasc Access. 2014 Jan-Feb;15(1):22-4.

18 Anastasiadou C, Megalopoulos A, Tasiopoulou K, Intzos V. A Rare Case of Brachial Artery Aneurysm Following Hemodialysis Fistula Ligation in a Transplanted Patient. Vasc Endovascular Surg. 2019 Jan;53(1): 71-4.

19 Murphy J, Bakran A. Late, acute presentation of a large brachial artery aneurysm following ligation of a Brescia-Cimino arteriovenous fistula. Eur J Vasc Endovasc Surg. 2010;39(1):123.

20 Ferrara D, Di Filippo M, Spalla F, Giribono AM, Viviani E, Santagata A, et al. Giant true Brachial Artery Aneurysm after Hemodialysis Fistula Closure in a Renal Transplant Patient. Case Rep Nephrol Dial. 2016 Nov;6(3):128-32.

21 Mestres G, Fontsere N, Yugueros X, Tarazona M, Ortiz I, Riambau V. Aneurysmal degeneration of the inflow artery after arteriovenous access for hemodialysis. Eur J Vasc Endovasc Surg. 2014 Nov;48(5):592-6.

22 Marconi M, Adami D. Giant true brachial artery aneurysm after hemodialysis fistula closure. Eur J Vasc Endovasc Surg. 2015 May;49(5):531.

23 Ventura M, Perilli L, Pisani F. True aneurysm of the brachial artery in a kidney transplant patient. Ital J Vasc Endovasc Surg. 2006;13:15-9.

24 Battaglia L, Bucci F, Battaglia M, Reddler A. Late occurrence of a large brachial artery aneurysm following closure of a hemodialysis arteriovenous fistula. Ann Vasc Surg. 2006 Jul;20(4):533-5.

25 Dinoto E, Bracale UM, Vitale G, Cacciatore M, Pecoraro F, Cassaro L, et al. Late, giant brachial artery aneurysm following hemodialysis fistula ligation in a renal transplant patient: case report and literature review. Gen Thorac Cardiovasc Surg. 2012 Nov;60(11):768-70. 


\section{Case Reports in Nephrology and Dialysis}

Case Rep Nephrol Dial 2020;10:57-64

(C) 2020 The Author(s). Published by S. Karger AG, Basel www.karger.com/cnd

Salerno et al.: Giant Brachial Aneurysm after Arteriovenous Fistula Ligation

26 Sapienza P, Borrelli V, Ciardi A, Sterpetti AV, Biacchi D, Tartaglia E, et al. Late occurrence of brachial artery aneurysm after the closure of a long-standing vascular access for hemodialysis: a pathogenetic hypothesis. J Cardiovasc Surg (Torino). 2014 Jun;55(3):445-7.

27 Sultana A, Torella F, McWilliams R, Bakran A. Axillary artery aneurysm following closure of haemodialysis fistula. A case report. J Cardiovasc Surg (Torino). 2007 Apr;48(2):197-9.

28 Basile C, Antonelli M, Libutti P, Teutonico A, Casucci F, Lomonte C. Is there a link between the late occurrence of a brachial artery aneurysm and the ligation of an arteriovenous fistula? Semin Dial. May-Jun 2011;24(3):341-2.

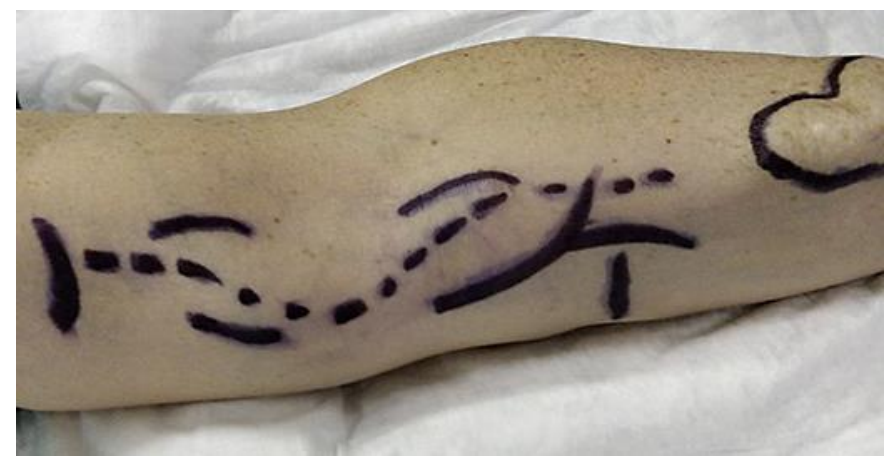

Fig. 1. Perioperative mapping.

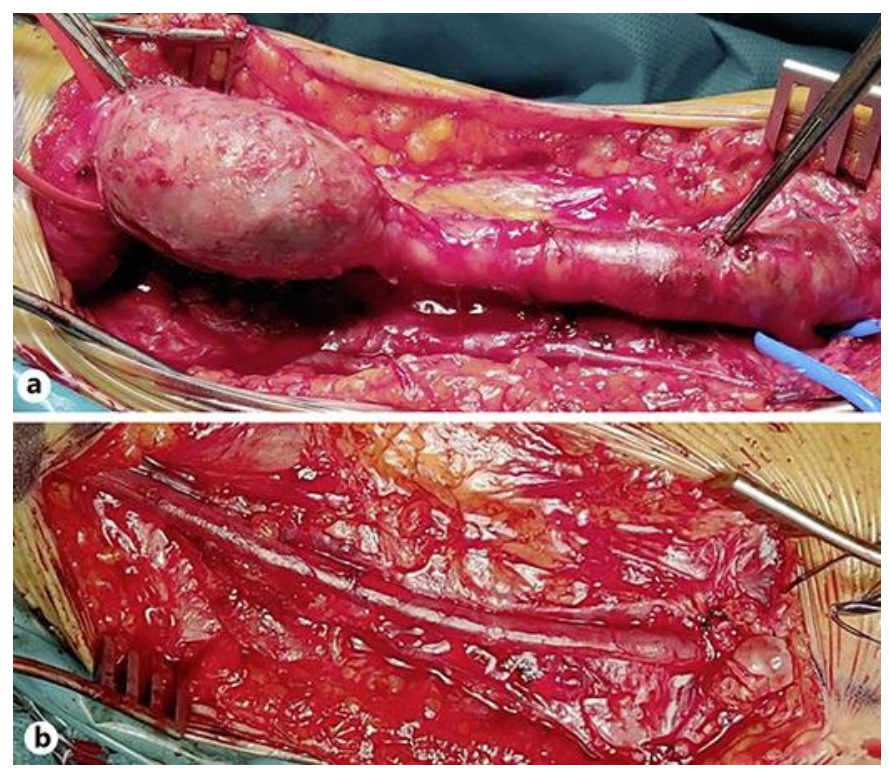

Fig. 2. a Complete isolation of the ulnar artery and aneurysm. b Aneurysm exclusion, great saphenous vein bypass. 


\section{Case Reports in \\ Nephrology and Dialysis}

(C) 2020 The Author(s). Published by S. Karger AG, Basel www.karger.com/cnd

Salerno et al.: Giant Brachial Aneurysm after Arteriovenous Fistula Ligation

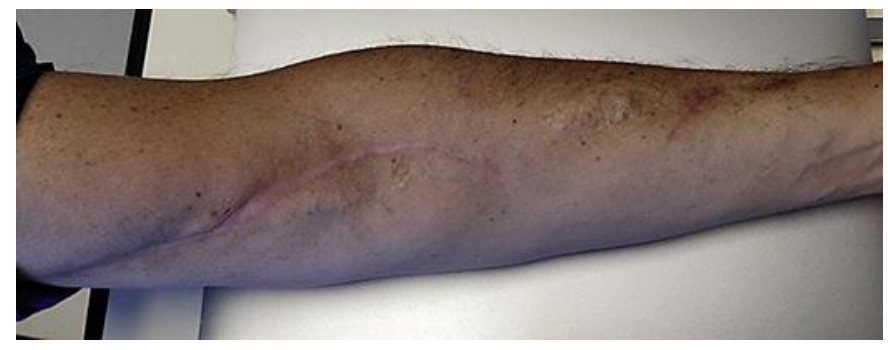

Fig. 3. Six-month control. 


\section{Case Reports in Nephrology and Dialysis}

Table 1. Summary of cases reports in the literature

\begin{tabular}{|c|c|c|c|c|c|c|c|}
\hline First author & Year & Patients & $\begin{array}{l}\text { Years after } \\
\text { ligation }\end{array}$ & Symptoms & Type of repair & Complications & $\begin{array}{l}\text { Follow-up, } \\
\text { months }\end{array}$ \\
\hline Anastasiadou & 2019 & 1 & 12 & painful, pulsatile mass & ipsilateral CV & none & $1,6,12$ \\
\hline Cleveland & 2015 & 1 & 4 & median neuropathy & ipsilateral CV & none & NR \\
\hline Teixeira & 2017 & 10 & NR & $\begin{array}{l}6 \text { localized pain and pulsatile mass; } 3 \text { subacute } \\
\text { ischemia/microembolization, } 1 \text { acute ischemia/ } \\
\text { aneurysm thrombosis }\end{array}$ & $\begin{array}{l}6 \text { GSVG; } 2 \text { ipsilateral CV; } \\
1 \text { ipsilateral BV; } 1 \text { PTFEG }\end{array}$ & $\begin{array}{l}1 \text { postoperative hematoma; } \\
1 \text { anastomotic stenosis }\end{array}$ & 69 \\
\hline Sapienza & 2014 & 1 & 15 & acute pain, swelling, distal microembolization & contralateral vein graft & none & 15 \\
\hline Dinoto & 2012 & 1 & 13 & pain, paresthesia, pulsatile mass & 1 PTFEG & none & 6 \\
\hline Orhan & 2019 & 1 & 10 & pain, swelling, paresthesia & $1 \mathrm{GSVG}$ & none & 24 \\
\hline Mestres & 2014 & 12 & $3,2,7$ & 6 pain; 1 distal embolization & $\begin{array}{l}3 \mathrm{CV} ; 4 \mathrm{BV} ; 2 \text { saphenous vein; } \\
2 \text { direct ligature; } 1 \text { end-to-end }\end{array}$ & $\begin{array}{l}1 \text { reoperation; } 1 \text { degeneration; } \\
1 \text { posttraumatic thrombosis; } \\
\text { bypass }\end{array}$ & 8.6 \\
\hline Marzelle & 2012 & 10 & NR & $\begin{array}{l}\text { pain, subacute ischemia, contained rupture, } \\
\text { swelling, pain, median nerve compression, pain } \\
\text { and swelling }\end{array}$ & $\begin{array}{l}2 \text { no intervention; } 2 \text { GSVG; } \\
5 \text { PTFEG; } 1 \text { allograft }\end{array}$ & $\begin{array}{l}6 \text { none; } 2 \text { aneurysmal; } \\
1 \text { occlusion }\end{array}$ & 20.3 \\
\hline Marconi & 2015 & 1 & 12 & none & PTFEG & none & 60 \\
\hline Kordzadeh & 2015 & 2 & 1 & blue finger, painful hands, pain, paresthesia & PTFEG; GSVG & none; none & $18 ; 18$ \\
\hline Ferrara & 2016 & 1 & NR & swelling and mild paresthetic symptoms & BV & none & 1 \\
\hline Garza & 2013 & 1 & NR & pain, paresthesia & GSVG & none & 6 \\
\hline Murphy & 2010 & 1 & 11 & pain, swelling & $\mathrm{CV}$ & NR & 12 \\
\hline Hale & 1994 & 1 & 3 & distal emboli & GSVG & NR & NR \\
\hline Nguyen & 2001 & 1 & 8 & paresthesias, digital emboli & GSVG & none & NR \\
\hline Battaglia & 2006 & 1 & 13 & swelling, mild pain & PTFEG & NR & NR \\
\hline Ventura & 2006 & 1 & NR & pain & PTFEG & NR & NR \\
\hline Sultana & 2007 & 1 & 17 & distal emboli, subjective coldness & axillary artery, GSVG & NR & 12 \\
\hline Chemla & 2010 & 5 & NR & $\begin{array}{l}\text { swelling, pain; none; swelling, pain; swelling, } \\
\text { pain; none }\end{array}$ & $\begin{array}{l}\text { end-to-end; GSVG; end-to-end; } \\
\text { GSVG; end-to-end }\end{array}$ & none & 14 \\
\hline Murphy & 2010 & 1 & 11 & swelling, pain & $\mathrm{CV}$ & none & 12 \\
\hline Basile & 2011 & 1 & 9 & swelling, pain & GSVG & none & 1 \\
\hline Khalid & 2014 & 3 & $5 ; 6 ; 20$ & $\begin{array}{l}\text { pain, pulsatile mass; paresthesias, distal emboli, } \\
\text { pain, pulsatile mass }\end{array}$ & GSVG; GSVG; ligation & 2 none; 1 arteriomegaly & $\begin{array}{l}6 \text { weeks; } \\
6 ; 12\end{array}$ \\
\hline Keuter & 2006 & 1 & NR & pain, swelling, claudication & GSVG & none & $\begin{array}{l}\text { postopera- } \\
\text { tive }\end{array}$ \\
\hline
\end{tabular}

BV, basilic vein; CV, cephalic vein; GSVG, great saphenous vein graft; NR, not reported; PTFEG, polytetrafluoroethylene graft. 